\title{
BMJ Open Prevalence and types of rectal douches used for anal intercourse among men who have sex with men in Brazil
}

\author{
Luiz Carlos Ribeiro Lamblet, ${ }^{1}$ Roberto José Carvalho da Silva ${ }^{2}$
}

To cite: Lamblet LCR, da Silva RJC. Prevalence and types of rectal douches used for anal intercourse among men who have sex with men in Brazil. BMJ Open 2017;7:e011122. doi:10.1136/ bmjopen-2016-011122

- Prepublication history and additional material are available. To view these files please visit the journal online (http://dx.doi. org/10.1136/bmjopen-2016011122).

Received 13 January 2016 Revised 14 August 2016 Accepted 1 September 2016
CrossMark

${ }^{1}$ Regional Council of Nursing, São Paulo, Brazil

${ }^{2}$ Reference and Training Center (CRT/AIDS), São Paulo, Brazil

Correspondence to

Dr Luiz Carlos Ribeiro Lamblet; luizlamblet7@gmail.com

\begin{abstract}
Introduction Rectal douching (RD) is practised among men who have sex with men (MSM), and various products and materials are used. There have been no studies in Brazil on this practice and its risks in the transmission of sexually transmitted infections and HIV.

Method Between June and August 2015, 401 MSM over the age of 18 were interviewed about their sexual practices associated with $\mathrm{RD}$ over the last 3 months. $\mathrm{RD}$ was associated with the reported sexual behaviour, and descriptive statistical analyses were conducted on the same.

Results Among the respondents, $85.6 \%$ identified themselves as men and $14.4 \%$ as transgender; 255 declared themselves to be white $(63.6 \%)$ and 104 to be mixed (25.9\%). From among those who had performed anal sex within the last 3 months $(n=369), 197$ reported having used RD (53.4\%). The most commonly used material was a shower hose (84.5\%) and the main product used was water (93\%). Of those interviewed, $94.5 \%$ never received guidelines from health professionals on this practice and its potential risks. Receptive anal intercourse and RD were found to be associated $(p<0.001)$.

Conclusions $\mathrm{RD}$ is a common practice among the MSM population. Health professionals must deepen their knowledge of this. We propose studies in Brazil on the practice of RD that-from that knowledge strategies for prevention and harm reduction - can be incorporated to the vulnerable populations.
\end{abstract}

\section{INTRODUCTION}

Rectal douching (RD) is commonly performed before anal intercourse among men who have sex with men $(\mathrm{MSM}) .{ }^{1-3}$ Several commercial and non-commercial devices, such as shower hoses, plastic bottles and syringes, are used. ${ }^{4}$ Tap water and homemade solutions are most commonly used in $\mathrm{RD}$. The primary reason for this practice is to clean the rectal cavity and therefore increase pleasure during sex. ${ }^{56}$ However, this practice can alter anal tissues and is associated with risky behaviour that may facilitate the transmission of sexually transmitted infections (STIs) and the HIV. ${ }^{1-46}$ HIV prevalence in Brazil is estimated to be $0.4 \%$ in the general population and $0.6 \%$ in the $15-49$ years age
Strengths and limitations of this study

Pioneering study in Brazil.

- Basis for discussion of the issue in the country.

- Unrepresentative sample of men who have sex with men.

group. Studies conducted between 2009 and 2013 in Brazil in the MSM population show an HIV prevalence rate of $10.5 \% .^{78}$ One of the main avenues of the spread of HIV among MSM is receptive anal intercourse (RAI). ${ }^{9}$ The proportion of cases among this group has tended to increase over the last 10 years, from $34.6 \%$ in 2004 to $43.2 \%$ in $2013 .{ }^{7}$ Social, biological, behavioural and epidemiological studies are needed to understand social and sexual practices among the MSM population and therefore trace new preventive strategies due to risks related to anal sex. ${ }^{5-11}$ This study aims to determine the prevalence of RD among MSM and to establish the main substances and materials associated with this practice.

\section{METHOD}

\section{Study site}

The study was conducted after being authorised by Report $\mathrm{n}^{\circ} 1100371$ (Certificate of Presentation for Ethical Consideration).

$\left.n^{\circ} 45107215.7 .0000 .5375\right)$ by the ethics and research committee of the Reference and Training Centre (CRT/AIDS). The study was conducted in three different clinics of the CRT/AIDS: the transgender clinic; the clinic for monitoring patients with HIV/AIDS and the serological testing and counselling clinic.

\section{Study population and inclusion criteria}

The study included a population of MSM from CRT/AIDS regardless of serological HIV status and of 18 years of age or older. Respondents were included in the survey after voluntarily agreeing to participate in the study during a visit to the above-mentioned 
Table 1 Gender identity, age, race/colour, education, monthly income, STI, drug abuse and anal sexual intercourse among MSM $(n=369)$

\begin{tabular}{|c|c|c|}
\hline & $n=369$ & $\%$ \\
\hline \multicolumn{3}{|l|}{ Gender identity } \\
\hline Man & 316 & 85.6 \\
\hline Transgender & 53 & 14.4 \\
\hline \multicolumn{3}{|l|}{ Age (in years) } \\
\hline $18-29$ & 175 & 47.4 \\
\hline $30-39$ & 129 & 35.0 \\
\hline $40-49$ & 51 & 13.8 \\
\hline $50-59$ & 12 & 3.3 \\
\hline $60-66$ & 2 & 0.5 \\
\hline \multicolumn{3}{|l|}{ Colour/race declared } \\
\hline White & 236 & 64.0 \\
\hline Mixed & 95 & 25.8 \\
\hline Black & 24 & 6.5 \\
\hline Other & 14 & 3.8 \\
\hline \multicolumn{3}{|l|}{ Formal education } \\
\hline Middle school finished/unfinished & 29 & 7.9 \\
\hline High school finished/unfinished & 86 & 23.3 \\
\hline $\begin{array}{l}\text { Undergraduate student (complete/ } \\
\text { incomplete)/graduated }\end{array}$ & 254 & 68.8 \\
\hline \multicolumn{3}{|l|}{ Total monthly income } \\
\hline BRL 0-2000 & 175 & 47.4 \\
\hline BRL 2001-4000 & 117 & 31.7 \\
\hline BRL over 4000 & 77 & 20.9 \\
\hline \multicolumn{3}{|l|}{ STI over the last 12 months } \\
\hline No & 234 & 63.4 \\
\hline Yes & 134 & 36.3 \\
\hline
\end{tabular}

$\begin{array}{lll}\text { I don't know } & 1 & 0.3\end{array}$

\begin{tabular}{|c|c|c|}
\hline \multicolumn{3}{|l|}{$\begin{array}{l}\text { Drug use during intercourse-last } \\
12 \text { months }\end{array}$} \\
\hline Yes & 186 & 50.4 \\
\hline No & 183 & 49.6 \\
\hline \multicolumn{3}{|l|}{ Anal intercourse } \\
\hline Insertive anal intercourse only & 79 & 21.4 \\
\hline RAI only & 86 & 23.3 \\
\hline RAl and insertive & 204 & 55.3 \\
\hline
\end{tabular}

MSM, men who have sex with men; RAl, receptive anal intercourse; STI, sexually transmitted infection.

clinics to receive treatment or guidelines or to be tested for STI/HIV.

\section{Participant recruitment for the study}

Participants were recruited by researchers trained in advance. After agreeing to participate in the study, participants were taken into a room specifically set aside for this study at each of the clinics. There, they received all necessary information about the aim of the study and signed the Terms of Clarification and Freely Consenting (TFCC). After receiving a copy of the TFCC, participants answered a digital questionnaire using a laptop. Participants who had difficulty completing the questionnaire digitally were assisted by a field researcher to use the computer.

\section{Data collection period}

Data were collected between 20 June and 20 August 2015.

\section{Research tools}

The questionnaire addressed epidemiological issues (sex, age, race, origin and residence), sexual orientation and sexual practices (frequency and partners) and the use of commercial and non-commercial products when performing RD (types of products used, frequency of these practices and risk behaviours). The questions addressed practices during the last 3 months and the last month before the interview, for better time reliability. After being adjusted, the questionnaire was formatted in the free application Google Docs and tested in a pre-test.

\section{Pre-test}

The researchers used five questionnaires to test understanding of the content and to carry out adjustments to the instrument. These questionnaires were not included in the study.

\section{Sample design and sample size}

The methodology used to calculate the sample came from a convenience sample, considering a CI of $95 \%$ and a maximum sampling error of $5 \%$ and an estimated prevalence of RD use of $50 \%$. For these calculations, the minimum sample should include 391 participants. The present study had 401 participants. ${ }^{12}$

\section{Statistical treatment of the sample}

Respondents were classified into two groups: those who use and those who do not use RD. Initially, the descriptive analysis of these two groups was conducted considering social and demographic variables. The following analysis was performed considering the variables for those in the group who performed RD. The categorical variables were tested with the $\chi^{2}$ test or Fisher's exact test. The OR and the respective CIs were estimated. The tests used were bi-flow rates and the level of significance was $\mathrm{p}<0.05$.

\section{RESULTS}

Of the research participants, $369(92 \%)$ had anal intercourse in the past 3 months (table 1). Among these, 86 reported to have performed RAI and $50.9 \%$ responded having had RAI and insertive intercourse. Among MSM who had had anal intercourse within the last 3 months, 314 resided in the State of São Paulo (85.1\%), 85.6\% identified themselves as men and $14.4 \%$ as transgender. Among these, 236 declared themselves to be white (64\%) and 104 declared themselves to be mixed (25.8\%). 
Table 2 Rectal douching (RD) use in the last 3 months: solutions, products and equipment

\begin{tabular}{lrr|}
\hline & \multicolumn{1}{c}{$\%$} \\
\hline RD $(\mathrm{n}=369)$ & 197 & 53.4 \\
\hline Yes & 172 & 46.6 \\
\hline No & & \\
\hline Home-made products $(\mathrm{n}=181)^{\star}$ & 33 & 18.2 \\
\hline Water + soap & 181 & 100.0 \\
\hline Water only & & \\
\hline Commercial products and solutions ( $\mathrm{n}=52)$ & 19 & 36.54 \\
\hline Fosfoenema & 7 & 13.46 \\
\hline In-M & 3 & 5.77 \\
\hline Minilax & 5 & 9.62 \\
\hline I don't remember & 3 & 5.77 \\
\hline Intimate liquid soap & 2 & 3.85 \\
\hline Glycerin suppository & 13 & 25.00 \\
\hline Disposable Kit purchased at pharmacy & & \\
\hline or store & & \\
\hline Home-made equipment used ( $n=232)^{*}$ & 199 & 85.78 \\
\hline Shower hose, bidet or sink & 22 & 9.48 \\
\hline Plastic water pump & 11 & 4.74 \\
\hline Plastic bottle & & \\
\hline
\end{tabular}

${ }^{*}$ Multiple choice.

Their average age in years was 31 . With regard to schooling, $68.8 \%$ are undergraduate students (initiated or completed college/university) or graduate students. With regard to monthly income, the most frequent group $(47.4 \%)$ had received an income of up to BRL 2000.00 Drugs used in connection with sex were: alcoholic drinks, marijuana, cocaine, viagra, cialis or levitra, poppers, ecstasy, ketamine, gamma-hydroxybutyric acid, crystal/ methamphetamine, crack and lysergic acyd diethylamide. STIs acquired in the last 12 months by respondents were: hepatitis; chlamydia; genital, rectal or anal warts (human papillomavirus); gonorrhoea; rectal gonorrhoea; genital herpes; syphilis and HIV.

According to table 2, of those who performed anal intercourse within the last 3 months $(n=369), 197$ reported RD use (53.4\%). The participants declared having used more than one type of product, solution or equipment to perform RD. To clean the rectal canal, the main solution used was water $(100.0 \%)$, followed by water and soap $(18.2 \%)$. The main equipment used was a shower hose, a bidet or a sink $(85.4 \%)$.

Among the 197 participants who used RD, the main reasons for the practice of RD before sex were cleanliness or hygiene and greater pleasure during anal intercourse. The main reasons among those who reported 'sometimes or never' performing RD before anal intercourse regarded it as 'unnecessary' or 'disliked the practice'. Among the RD after anal intercourse group, respondents
Table 3 Reasons for the practice of rectal douching (RD) and difficulties associated with RD before and after receptive anal intercourse in the last 3 months $(n=197)^{*}$

\begin{tabular}{|c|c|c|}
\hline & $\mathbf{n}$ & $\%$ \\
\hline \multicolumn{3}{|l|}{ Reason-RD always BEFORE } \\
\hline Cleaning/hygiene & 84 & 42.6 \\
\hline More pleasurable anal intercourse & 34 & 17.2 \\
\hline It is a preference of the partner & 6 & 3.0 \\
\hline Constipation & 1 & 0.5 \\
\hline \multicolumn{3}{|c|}{ Reason-RD sometimes or never BEFORE } \\
\hline Unnecessary & 69 & 35.0 \\
\hline Do not like it & 53 & 26.9 \\
\hline Unplanned sexual encounter & 46 & 23.4 \\
\hline Did not have time & 43 & 21.8 \\
\hline Have no information on $\mathrm{RD}$ & 6 & 3.0 \\
\hline Think it is unhealthy & 1 & 0.5 \\
\hline \multicolumn{3}{|l|}{ Reason-RD always AFTER } \\
\hline Cleaning/hygiene & 21 & 10.7 \\
\hline Partner did not use condom & 7 & 3.6 \\
\hline Previous RD was not adequate & 1 & 0.5 \\
\hline \multicolumn{3}{|l|}{ Reason-RD sometimes or never AFTER } \\
\hline Unnecessary & 153 & 77.7 \\
\hline I had sex with a condom & 136 & 69.0 \\
\hline Unplanned sexual encounter & 34 & 17.2 \\
\hline Ignorance & 4 & 2.0 \\
\hline Hygiene & 3 & 1.5 \\
\hline I don't like it & 2 & 1.0 \\
\hline I evacuated afterwards & 1 & 0.5 \\
\hline I've read that it isn't recommended & 1 & 0.5 \\
\hline I used a laxative product & 1 & 0.5 \\
\hline \multicolumn{3}{|l|}{ Difficulties-RD } \\
\hline Pain & 33 & 16.8 \\
\hline Bleeding & 13 & 6.6 \\
\hline Trauma/injury to the anus & 13 & 6.6 \\
\hline Cramps & 4 & 2.0 \\
\hline Nuisance & 2 & 1.0 \\
\hline Burnt & 2 & 1.0 \\
\hline Medical contraindication & 1 & 0.5 \\
\hline Presence of haemorrhoids & 1 & 0.5 \\
\hline Dryness & 1 & 0.5 \\
\hline
\end{tabular}

*Multiple choice.

mainly regarded it 'unnecessary' or declared themselves to 'have used a condom'. The greatest difficulties reported when performing RD were pain and bleeding (table 3 ).

In simple logistic regression, there was an association between RD use among those who have RAI $(p<0.001)$, as seen in table 4 . 


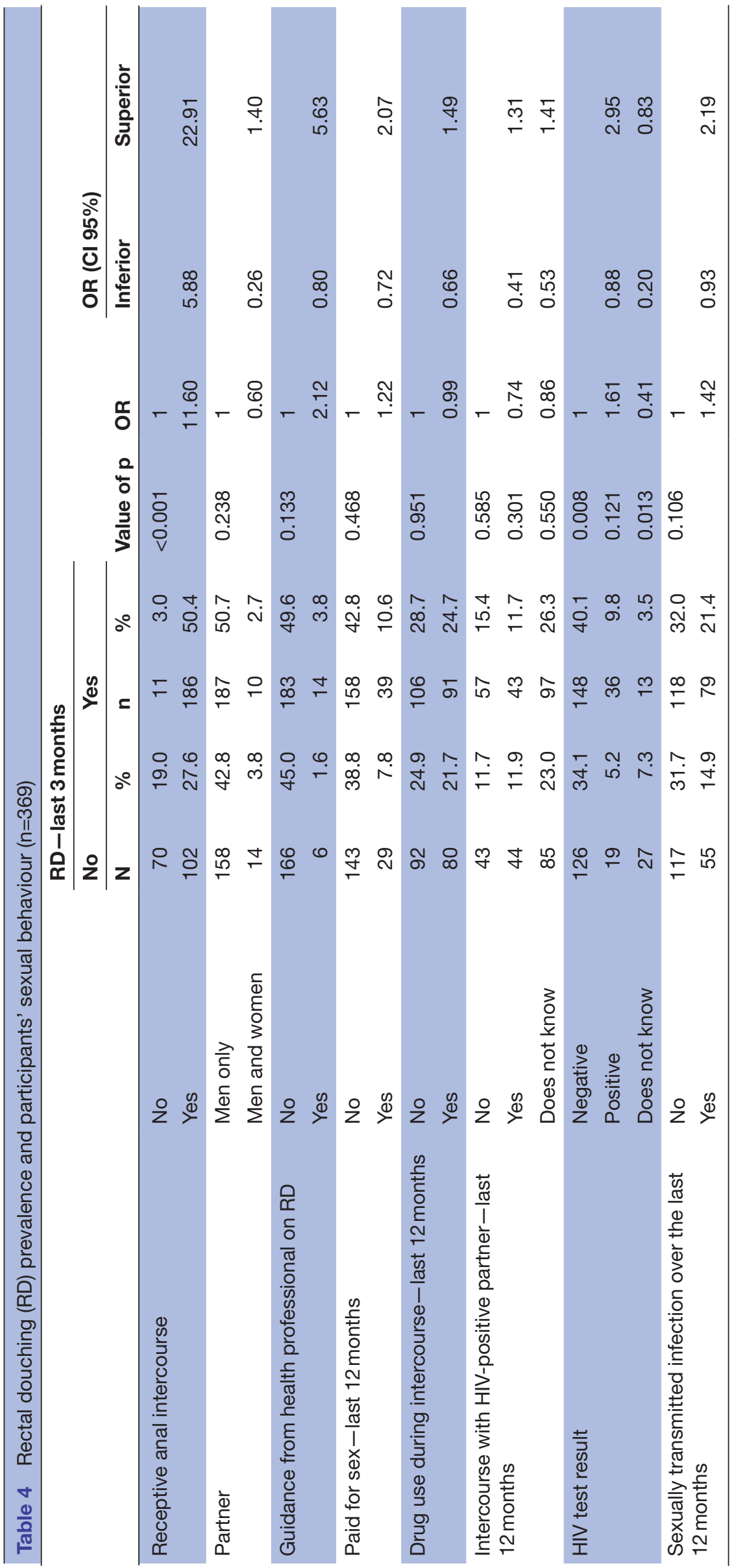

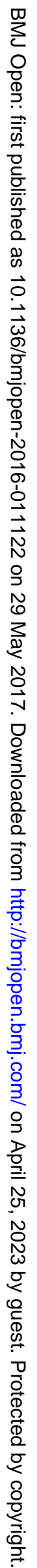




\section{DISCUSSION}

The results of this study indicate that the practice of $\mathrm{RD}$ is common among the MSM population before RAI, with a prevalence of $53.4 \%$. These results are consistent with other studies showing prevalence of 52-66\%. ${ }^{6} 1113$ This study has revealed that RD is performed with homemade products and materials and objects not designed for this purpose. Among those who used non-commercial products $(n=233), 199$ used a shower hose to introduce water into the anus $(84.5 \%)$. These results are consistent with a study conducted with participants from five continents concerning RD-related practices, where $93 \%$ of the respondents $(n=1339)$ reported using non-commercial products $(93 \%)$ and water $(82 \%)$ to perform RD. The study indicates a $74 \%$ increased risk of STI/HIV between those who use RD and those who do not perform it $(\mathrm{OR}=1.74 ; 95 \% \mathrm{CI}, 1.01$ to 3.00$) .{ }^{6}$ These findings indicate that RD is associated with risky behaviour. Studies on the MSM population commonly investigate the prevalence of STI/HIV among this population; however, these studies do not usually address the behavioural aspects related to the information on beliefs and values of sexual practices in specific populations of greater vulnerability. A study on the use of RD in 16 US cities conducted through an online questionnaire with 4992 MSM respondents indicated that $52 \%$ use RD, $43.3 \%$ perform it often and $87.6 \%$ use RD before sex and $27.4 \%$ after sex. Among those who performed RD after sexual intercourse, the main reason was to prevent STI/HIV infection (12.7\%). The main product used was tap water $(65.7 \%)$. The authors question the contradiction in the risk of changing the rectal epithelium attributed to the use of water to perform RD, considering that intimate lubricants are water based. ${ }^{13}$ This question is relevant because scientific literature generally affirms that RD removes beneficial bacteria and the surface layer of the intestinal epithelium, which could potentially increase the risk of HIV transmission among MSM. ${ }^{513}$ However, research on these practices is insufficient, even though several guidelines on the practice of anal intercourse are provided to patients by health professionals. ${ }^{14}$ Our study demonstrated that $94.6 \%$ of the participants have never received professional guidance on the practice of RD. Health professionals should deepen their knowledge of RD in the MSM population. New prevention strategies have been proposed, such as pre-exposure oral therapy. The use of gel or rectal microbicides in showers has also been studied in the MSM population. Understanding the use of $\mathrm{RD}$ in Brazil will determine the feasibility of introducing these possible HIV transmission prevention strategies in this vulnerable population. ${ }^{1-415}$ The study was conducted at a state reference research centre for prevention and treatment of STI and HIV, which complies with the Ministry of Health's public policies for the prevention and treatment of patients with STI and HIV in Brazil. The public health policy of the country guarantees serological tests for the detection of HIV and other STIs as well as treatment and follow-up through the Unified Health System to the population. Collecting data in such institutions allowed the recruitment of patients undergoing the antiretroviral therapy treatment and members of the MSM population who were in the clinic either to get serologically tested or to receive guidance from health professionals. This was a large, clinic-based sample, but the findings cannot be generalised for the whole MSM population. New studies on the subject should be conducted to understand this practice in the various regions of the country. The instrument used for data collection (online questionnaire) provided quick responses and proved to be a practical way of organising the collected data. The room set aside for the task and the use of a computer prevented external interference that could inhibit responses.

\section{CONCLUSIONS}

The use of RD is a common practice in the MSM population. Health professionals need to deepen their knowledge of this matter. Further studies are needed to understand this practice in Brazil among the MSM population. From these studies, new knowledge and strategies may be proposed for the prevention of STI/HIV in this vulnerable population.

Contributors LCRL: study conception and design, interpretation of results, drafting of manuscript; RJCS: supervision of data analysis, interpretation of results and manuscript preparation.

Competing interests None declared.

Ethics approval Research ethics committee (CEP) of the Center for Reference and Training - CRT/AIDS, State of So Paulo, Brazil.

Provenance and peer review Not commissioned; externally peer reviewed.

Data sharing statement 0 ther data can be requested by emailing the corresponding author.

Open Access This is an Open Access article distributed in accordance with the Creative Commons Attribution Non Commercial (CC BY-NC 4.0) license, which permits others to distribute, remix, adapt, build upon this work non-commercially, and license their derivative works on different terms, provided the original work is properly cited and the use is non-commercial. See: http://creativecommons.org/ licenses/by-nc/4.0/

(C) Article author(s) (or their employer(s) unless otherwise stated in the text of the article) 2017. All rights reserved. No commercial use is permitted unless otherwise expressly granted.

\section{REFERENCES}

1. Carballo-Diéguez A, Bauermeister JA, Ventuneac A, et al. The use of rectal douches among HIV-uninfected and infected men who have unprotected receptive anal intercourse: implications for rectal microbicides. AIDS Behav 2008;12:860-6.

2. Calabrese SK, Rosenberger JG, Schick VR, et al. An event-level comparison of risk-related sexual practices between black and other-race men who have sex with men: condoms, semen, lubricant, and rectal douching. AIDS Patient Care STDS 2013;27:77-84.

3. Carballo-Diéguez A, Bauermeister J, Ventuneac A, et al. Why rectal douches may be acceptable rectal-microbicide delivery vehicles for men who have sex with men. Sex Transm Dis 2010;37:228-33.

4. Galea JT, Kinsler JJ, Imrie J, et al. Rectal douching and implications for rectal microbicides among populations vulnerable to HIV in South America: a qualitative study. Sex Transm Infect 2014;90:33-5.

5. Schmelzer M, Schiller LR, Meyer R, et al. Safety and effectiveness of large-volume Enema solutions. Appl Nurs Res 2004;17:265-74.

6. Javanbakht M, Stahlman S, Pickett J, et al. Prevalence and types of rectal douches used for anal intercourse: results from an international survey. BMC Infect Dis 2014;14:95. 
7. Ministry of Health. Secretariat of Health Surveillance. Epidemiological Bulletin. Brasília: Ministry of Health, 2014. Portal about AIDS, sexually transmitted diseases and viral hepatitis.

8. The Brazilian Response to HIV and AIDS. Global AIDS Response Progress Reporting (GARPR) Narrative Report. Brazil: Ministry of Health. 2015. http://www.unaids.org/sites/default/files/country/ documents/BRA_narrative_report_2015.pdf.

9. Beyrer C, Baral SD, van Griensven F, et al. Global epidemiology of HIV infection in men who have sex with men. Lancet 2012;380:367-77.

10. Malta M, Magnanini MM, Mello MB, et al. HIV prevalence among female sex workers, drug users and men who have sex with men in Brazil: a systematic review and meta-analysis. BMC Public Health 2010;10:317.

11. Rosenberger JG, Herbenick D, Van Der Pol B, et al. O2-S4.06 Exploring enema practices among men who have sex with men in the USA: implications for sexual health. Sex Transm Infect 2011;87:A63.

12. Silva NN. Amostragem probabilística. $2^{\text {a }}$. Ed. São Paulo: Edusp, 2001:1-135.

13. Noor SW, Rosser BR. Enema use among men who have sex with men: a behavioral epidemiologic study with implications for HIV/STI prevention. Arch Sex Behav 2014;43:755-69.

14. Schilder AJ, Orchard TR, Buchner CS, et al. Insert Discourse: rectal Douching among Young HIV-Positive and HIV-Negative men who have sex with men in Vancouver, Canada. Sex Cult 2010;14:327-43.

15. Galea JT, Kinsler JJ, McLean S, et al. Rectal Douching prevalence and Practices among peruvian men who have sex with men and transwomen: implications for rectal microbicides. AIDS Behav 2015. Epub ahead of print. 